\title{
Quality of life after different surgical procedures for the treatment of spinal metastases: results of a single-center prospective case series
}

\author{
Godard C. W. de Ruiter, MD, PhD, Claudine O. Nogarede, NP, Jasper F. C. Wolfs, MD, and \\ Mark P. Arts, MD, PhD \\ Department of Neurosurgery, Medical Center Haaglanden, The Hague, The Netherlands
}

OBJECTIVE The performance of surgery for spinal metastases is rapidly increasing. Different surgical procedures, ranging from stabilization alone to stabilization combined with corpectomy, are thereby performed for various indications. Little is known about the impact of these different procedures on patient quality of life (QOL), but this factor is crucial when discussing the various therapeutic options with patients and their families. Thus, the authors of this study investigated the effect of various surgical procedures for spinal metastases on patient QOL.

METHODS The authors prospectively followed a cohort of 113 patients with spinal metastases who were referred to their clinic for surgical evaluation between July 2012 and July 2014. Quality of life was assessed using the EQ-5D at intake and at 3, 6, 9, and 12 months after treatment.

RESULTS Nineteen patients were treated conservatively, 41 underwent decompressive surgery with or without stabilization, 47 underwent a piecemeal corpectomy procedure with stabilization and expandable cage reconstruction, and 6 had a stabilization procedure without decompression. Among all surgical patients, the mean EQ-5D score was significantly increased from 0.44 pretreatment to 0.59 at 3 months after treatment $(p<0.001)$. Mean EQ-5D scores at 1 year after surgery further increased to 0.84 following decompression with stabilization, 0.74 after corpectomy with stabilization, and 0.94 after stabilization without decompression. Frankel scores also improved after surgery. There were no significant differences in improvements in EQ-5D scores and Frankel grades among the different surgical procedures. In addition, mortality and complication rates were similar.

CONCLUSIONS Quality of life can improve significantly after various extensive and less extensive surgical procedures in patients with spinal metastases. The relatively invasive corpectomy procedure, as compared with alternative less invasive techniques, does not negatively affect outcome.

https://thejns.org/doi/abs/10.3171/2016.6.FOCUS16150

KEY WORDS spinal metastases; surgery; vertebrectomy; corpectomy; quality of life

$\mathrm{D}$ ECIDING which surgery to perform in patients with spinal metastases is often based on several factors such as indication (for example, pain, spinal cord compression, instability, tumor control), primary tumor type, presence of metastases, and condition of the patient. Several models have been developed to guide the surgeon in this selection process. ${ }^{3,23,24,26}$ Most of these models are based on the patient's life expectancy. Little is known about the effect of various surgical procedures on patient quality of life (QOL) ${ }^{18}$ but this factor is crucial when discussing the different therapeutic options with patients and their relatives. In this study we investigated the effect of various surgical procedures for spinal metastases on patient QOL after surgery ranging from minimally invasive stabilization to piecemeal corpectomy with expandable cage reconstruction.

ABBREVIATIONS ASA = American Society of Anesthesiologists; EORTC = European Organisation for Research and Treatment of Cancer; GSTSG = Global Spine Tumour Study Group; HRQOL = health-related quality of life; KPS = Karnofsky Performance Scale; QOL = quality of life; SINS = Spinal Instability Neoplastic Score; VBS = vertebral body stent. 


\section{Methods}

\section{Patient Population}

The institutional review board of our hospital approved this study. All patients with spinal metastases who were referred to our center for surgical evaluation between July 2012 and July 2014 were asked by our specialized nurse practitioner (C.O.N.) to participate in this study. Informed consent was obtained in 113 of 125 consecutive patients. Deciding on the best treatment strategy was done in a multidisciplinary setting (oncologist, radiotherapist, and neurosurgeon) and was based on several prognostic factors, including life expectancy (at least 3-6 months) and physical condition of the patient (Karnofsky Performance Scale $^{19}$ [KPS] score $>60$ and American Society of Anesthesiologists ${ }^{1}$ [ASA] Score I-III). The exact surgical procedure to perform was determined by our team of spinal surgeons. Stabilization without decompression was performed in cases of instability without spinal cord or nerve root compression. Decompression and debulking was performed in cases of spinal cord or nerve compression. Stabilization was also performed in cases of impending instability before and/or after the procedure. Indications for a piecemeal corpectomy procedure were 1) vertebral body involvement $>50 \%, 2$ ) vertebral body collapse with severe kyphosis $>20^{\circ}$, and 3) local tumor control. Prerequisite for a corpectomy was a life expectancy of at least 6 months because this procedure is more invasive and therefore has a longer recovery period than, for example, decompressive surgery with stabilization (for which the prerequisite life expectancy was 3 months).

Of the 113 patients included in this study, 19 were treated conservatively, 4 patients underwent decompressive surgery without stabilization, 37 patients underwent decompressive surgery with stabilization, 47 underwent corpectomy with instrumentation, and 6 had a stabilization procedure without decompression. The 4 patients who underwent a decompressive procedure without stabilization were added to the group that had decompressive surgery with stabilization for comparisons with the other groups. Baseline characteristics of all patients are presented in Table 1. Indications for surgery were spinal cord or cauda equina compression (64 cases), spinal instability without cord or cauda compression (17), decompression for radicular pain (9), and tumor control (4). The corpectomy procedure was more frequently performed in cases of spinal cord or cauda compression with spinal instability (21 cases), whereas decompression and fixation were more frequently performed in cases without instability (24 cases). All corpectomy procedures for thoracolumbar spinal metastases (except 1) were performed via a posterior approach with piecemeal resection of the tumor, remnants of the vertebral body, and adjacent intervertebral body discs. The defect was subsequently reconstructed with a titanium expandable cage. In cases of stabilization without decompression, conventional open instrumentation was used in the craniocervical region and minimally invasive percutaneous instrumentation was used in the thoracolumbar spine. All screws (open and minimally invasive) were placed with a spinal navigation system (O-arm, Medtronic).

\section{Outcome Assessment}

All patients were followed-up 1 year after surgery. Quality of life was assessed using the EQ-5D at intake and at 3, 6, 9, and 12 months after treatment. ${ }^{12}$ In addition, Frankel grade ${ }^{17}$ and the presence of urinary incontinence were documented. For the surgically treated group, the ASA score was also noted.

\section{Statistical Analysis}

Statistical analysis was performed using SPSS software (IBM Corp.). Results were compared using 1-way ANOVA with Bonferroni post hoc test. Differences in EQ-5D results among the surgical groups and for the different indications were compared, as was the indication for surgery and the Frankel grade at intake (Frankel Grades A, B, and $\mathrm{C}$ versus Grades $\mathrm{D}$ and $\mathrm{E})$. In addition, paired analysis was performed to investigate improvement in EQ-5D scores for the patients who were still alive at the different time points.

\section{Results}

\section{Comparisons for Different Surgical Procedures}

The mean EQ-5D (0.59) for the entire group of patients significantly increased 3 months after treatment compared with the mean pretreatment score $(0.44 ; \mathrm{p}<0.001)$. Improvement in the EQ-5D score at 3 months was better in the fixation-only and corpectomy groups ( 0.68 and 0.62 , respectively) than in the decompression plus fixation group (0.55), although this difference was not significant $(\mathrm{p}=$ 0.74). The mean EQ-5D score further increased to 0.84 at 1 year after decompression plus fixation, 0.74 at 1 year after corpectomy, and 0.94 at 1 year after fixation alone (Table 2). Analysis of indications for surgery showed no significant difference in outcome for radicular pain, spinal cord or cauda equina compression, and instability without cord or cauda compression. (Tumor control was excluded from analysis because of the small number of patients.) Comparison of the patient groups with Frankel Grades A-C at intake versus those with Frankel Grades D and E also revealed no significant difference.

Frankel grades improved after surgery. There was no difference in improvement between the decompression plus stabilization and the corpectomy procedures (Fig. 1). The most frequent recovery was from Frankel Grade $\mathrm{C}$ to $\mathrm{D}$ at 3 months after surgery.

\section{Analysis of Short-Term Survival}

Mortality rate within 3 months was $16 \%$ (15 of 94) for the entire surgical group versus 68\% (13 of 19 patients) for the group treated conservatively. Because follow-up for the conservatively treated group was limited to 6 patients, comparative analysis with EQ-5D results was not performed for this group. Detailed analysis of the 15 patients who died $<3$ months after surgery showed no difference in the procedure performed; 7 patients had undergone decompression plus stabilization, and 8 patients had had a corpectomy. The most frequent primary tumor was lung cancer (33\%), followed by kidney cancer (20\%). The mean age (66 years old) in this short-term survival group was not different from that of the entire surgery group. 
TABLE 1. Summary of characteristics in 113 patients treated conservatively or surgically for spinal metastasis

\begin{tabular}{|c|c|c|c|c|}
\hline Parameter & Conservative Treatment & Decompression w/ or w/o Stabilization & Corpectomy & Stabilization Only \\
\hline No. of patients & 19 & 41 & 47 & 6 \\
\hline \multicolumn{5}{|l|}{ Indications for surgery } \\
\hline Compression of spinal cord or cauda equina & 16 & 33 & 31 & \\
\hline Instability & 1 & 4 & 7 & 6 \\
\hline Radicular pain & 2 & 3 & 6 & \\
\hline Tumor control & & 1 & 3 & \\
\hline Mean age in yrs & 61 & 69 & 63 & 66 \\
\hline \multicolumn{5}{|l|}{ Frankel grade } \\
\hline A & & $1(2 \%)$ & $0(0 \%)$ & \\
\hline B & $3(16 \%)$ & $0(0 \%)$ & $1(2 \%)$ & \\
\hline C & $6(32 \%)$ & $19(46 \%)$ & $13(28 \%)$ & \\
\hline $\mathrm{D}$ & $4(21 \%)$ & $9(22 \%)$ & $12(26 \%)$ & \\
\hline$E$ & $6(31 \%)$ & $12(29 \%)$ & $20(43 \%)$ & $6(100 \%)$ \\
\hline Mean SINS & & 7.1 & 10.1 & 10.7 \\
\hline Mean KPS score & 66 & 76 & 81 & 83 \\
\hline Mean ASA status & NA & 2.3 & 2.1 & 2.7 \\
\hline Urinal incontinence at intake & $11(58 \%)$ & $9(22 \%)$ & $13(28 \%)$ & $0(0 \%)$ \\
\hline \multicolumn{5}{|l|}{ Primary tumor } \\
\hline Breast & $1(5 \%)$ & $8(20 \%)$ & $6(13 \%)$ & $1(17 \%)$ \\
\hline Prostate & $3(16 \%)$ & $5(12 \%)$ & $1(2 \%)$ & $2(17 \%)$ \\
\hline Lung & $5(26 \%)$ & $7(17 \%)$ & $7(15 \%)$ & \\
\hline Colon & $1(5 \%)$ & $4(10 \%)$ & $11(23 \%)$ & \\
\hline Multiple myeloma & $1(5 \%)$ & $6(15 \%)$ & $11(23 \%)$ & $4(67 \%)$ \\
\hline \multicolumn{5}{|l|}{ Metastases } \\
\hline None & $3(16 \%)$ & $18(44 \%)$ & $21(45 \%)$ & $3(50 \%)$ \\
\hline Visceral & $4(21 \%)$ & $4(10 \%)$ & $6(13 \%)$ & \\
\hline Bone & $6(32 \%)$ & $13(32 \%)$ & $12(26 \%)$ & $3(50 \%)$ \\
\hline Both & $6(32 \%)$ & $5(12 \%)$ & $7(15 \%)$ & \\
\hline Unknown & $0(0 \%)$ & $1(2 \%)$ & $1(2 \%)$ & \\
\hline \multicolumn{5}{|l|}{ Location spinal metastasis } \\
\hline Cervical & $1(5 \%)$ & $2(5 \%)$ & $7(15 \%)$ & $3(50 \%)$ \\
\hline Thoracic & $12(63 \%)$ & $31(76 \%)$ & $22(47 \%)$ & $2(33 \%)$ \\
\hline Lumbar & $6(32 \%)$ & $8(19 \%)$ & $18(38 \%)$ & $1(17 \%)$ \\
\hline 2 adjacent levels & $4(21 \%)$ & $3(7 \%)$ & $3(6 \%)$ & $1(17 \%)$ \\
\hline 3 adjacent levels & $3(16 \%)$ & $4(10 \%)$ & $0(0 \%)$ & $0(0 \%)$ \\
\hline Mean duration of surgery in mins & NA & 138 & 222 & 120 \\
\hline \multicolumn{5}{|l|}{ Complications } \\
\hline Total no. of patients & & $14(34 \%)$ & $18(38 \%)$ & \\
\hline Increased neurological deficit & & $1(2 \%)$ & $0(0 \%)$ & \\
\hline Dural defect & & $2(5 \%)$ & $4(9 \%)$ & \\
\hline Pleural defect & & & $1(2 \%)$ & \\
\hline Wound infection & & $4(10 \%)$ & $2(4 \%)$ & \\
\hline Screw malposition/pullout & & $1(2 \%)$ & $1(2 \%)$ & \\
\hline $\begin{array}{l}\text { Other (pneumonia, urinary tract infection, } \\
\text { delirium) }\end{array}$ & & $7(17 \%)$ & $10(21 \%)$ & $1(17 \%)$ \\
\hline
\end{tabular}

NA = not applicable.

However, the mean KPS score (71) was significantly lower than that (79) for the entire surgical group $(\mathrm{p}<0.001)$. The mean estimated 6-month survival probability according to
Bartels scoring system was 0.33 , which was comparable with that for the patients who died $<6$ months $(0.70),<9$ months (0.64), and $<12$ months (0.77) after surgery. 
TABLE 2. Mortality, response rate to EQ-5D questionnaire, and mean results for $E Q-5 D$ after different surgical procedures for spinal metastases

\begin{tabular}{cccc}
\hline $\begin{array}{c}\text { Surgical Procedure \& } \\
\text { Time Point }\end{array}$ & $\begin{array}{c}\text { Mortality } \\
\text { Rate }\end{array}$ & $\begin{array}{c}\text { Questionnaire } \\
\text { Response } \\
\text { Rate }\end{array}$ & $\begin{array}{c}\text { Mean } \\
\text { Results of } \\
\text { EQ-5D }\end{array}$ \\
\hline $\begin{array}{c}\text { Decompression \& stabilization } \\
\text { (41 patients) }\end{array}$ & & & \\
\hline Intake & & & 0.47 \\
\hline 3 mos & $17 \%$ & $88 \%$ & 0.55 \\
\hline 6 mos & $24 \%$ & $87 \%$ & 0.59 \\
\hline 9 mos & $37 \%$ & $81 \%$ & 0.57 \\
\hline 12 mos & $49 \%$ & $76 \%$ & 0.84 \\
\hline Corpectomy (47 patients) & & & \\
\hline Intake & & & 0.42 \\
\hline 3 mos & $17 \%$ & $82 \%$ & 0.62 \\
\hline 6 mos & $21 \%$ & $78 \%$ & 0.61 \\
\hline 9 mos & $30 \%$ & $82 \%$ & 0.67 \\
\hline 12 mos & $30 \%$ & $79 \%$ & 0.74 \\
\hline Stabilization alone $(6$ patients) & & & \\
\hline Intake & & & 0.37 \\
\hline 3 mos & $17 \%$ & $100 \%$ & 0.68 \\
\hline 6 mos & $17 \%$ & $100 \%$ & 0.67 \\
\hline 9 mos & $17 \%$ & $100 \%$ & 0.83 \\
\hline 12 mos & $17 \%$ & $100 \%$ & 0.94 \\
\hline
\end{tabular}

\section{Discussion}

\section{Quality of Life and Selection of Patients for Surgery}

This study shows that QOL in patients with spinal metastases improves after surgical treatment and that this improvement is sustained for the period of 1 year. Other studies have shown similar results for this improvement in QOL, ${ }^{13,21,28}$ although it is difficult to compare the results of these studies because different outcome measures were used, including functional outcome measures (such as the Frankel classification and visual analog scale), ${ }^{13,18}$ validated health-related QOL (HRQOL) outcome measures (such as the European Organisation for Research and Treatment of Cancer [EORTC] QLQ-30 questionnaire), ${ }^{13,21}$ and utility scales (such as the Health Utilities Index Mark 3 [HUI3] and EQ-5D). ${ }^{7,13}$ In the present study, we chose to use the EQ-5D for the analysis of HRQOL because, as stated by the Global Spine Tumour Study Group (GSTSG), ${ }^{9}$ it can be used more easily, even by telephone. The advantage over more extended questionnaires, such as the EORTC QLQ-30, is that its ease of use increases the response rate, which in our study was around $80 \%$ at all time points (Table 2). Recently, the GSTSG, which we are part of, reported the results for a cohort of 922 patients. ${ }^{7}$ A major finding in that study was that Frankel grade and KPS score were important predictors for QOL after surgery. Shortcomings of that study, however, were the high loss to follow-up (recorded follow-up of only $40 \%$ of patients after 1 year), a potential difference in referral to the various centers that participated in the study (different indications for surgery), a difference in the selection of patients for surgery, and the fact that different procedures were performed for the same indication. Most patients in our study presented with spinal metastases with cord or cauda equina compression (Table 1). Other indications included instability, pain, or local tumor control. As regards instability, the Spinal Instability Neoplastic Score (SINS) is generally used by our radiotherapists to determine which patient needs consultation because of potential instability. ${ }^{14-16}$ Patients with radicular pain are sometimes referred when conservative treatment fails. Referral for resection of solitary metastases is still a rare indication at our center, but the number of cases increase as the systematic therapies and survival of cancer patients improve. ${ }^{22}$

The decision of whether to offer surgery to patients and their relatives was made by a team of spinal surgeons. In cases in which the patient was considered to be a potential candidate, the patient was transferred to our department so that we could determine his or her condition, including the KPS score. Biopsy was performed first in cases in which there was no known primary tumor but only if there was no progressive neurological deficit. Life expectancy was determined together with the oncologist. If life expectancy was more than 3-6 months, the option of surgery was discussed with the patient and their families. Despite this rigorous selection process, $16 \%$ of our patients still died within a 3-month period after surgery. A possible explanation for this could be that life expectancy in these patients was overestimated. In our experience, life expectancy is often overestimated by oncologists, especially since the Patchell et al. study has shown beneficial results for surgical treatment combined with radiotherapy as compared with radiotherapy alone in patients with a life expectancy of at least 3 months. ${ }^{20}$ Because of this frequent overestimation of life expectancy, we now use Bartels' prognostic model, which was recently validated in a group of our patients. ${ }^{2}$

The high tendency to opt for surgery was probably one of the reasons why comparison with conservatively treated patients in our study was not possible (in addition to the high mortality rate). The only study to date that has compared QOL for surgery versus nonsurgery was performed by Wu et al. ${ }^{28}$ In that study a significantly higher total QOL score was found in the surgical group.

\section{Comparison of Different Surgical Procedures}

An interesting finding in our study was that the EQ-5D score did not differ for the various surgical procedures, not even for the relatively more invasive corpectomy procedure. We previously published data on an initial series of 60 patients who had been treated with corpectomy between December 2005 and May 2011. ${ }^{10}$ Since then we have made significant improvements in performing this procedure with a shorter operating time (mean 3.7 hours instead of 5.9) and a lower complication rate (neurological deficit $0 \%$ instead of $12 \%$ and an infection rate of $4 \%$ instead of $10 \%$ ). Therefore, we believe that this procedure can be safely performed and has an advantage over decompression plus stabilization in that the height of a collapsed vertebra can be restored, as can the angle of kyphosis. As an alternative to the corpectomy procedure, vertebral body stents (VBSs) can be placed to correct height and kypho- 


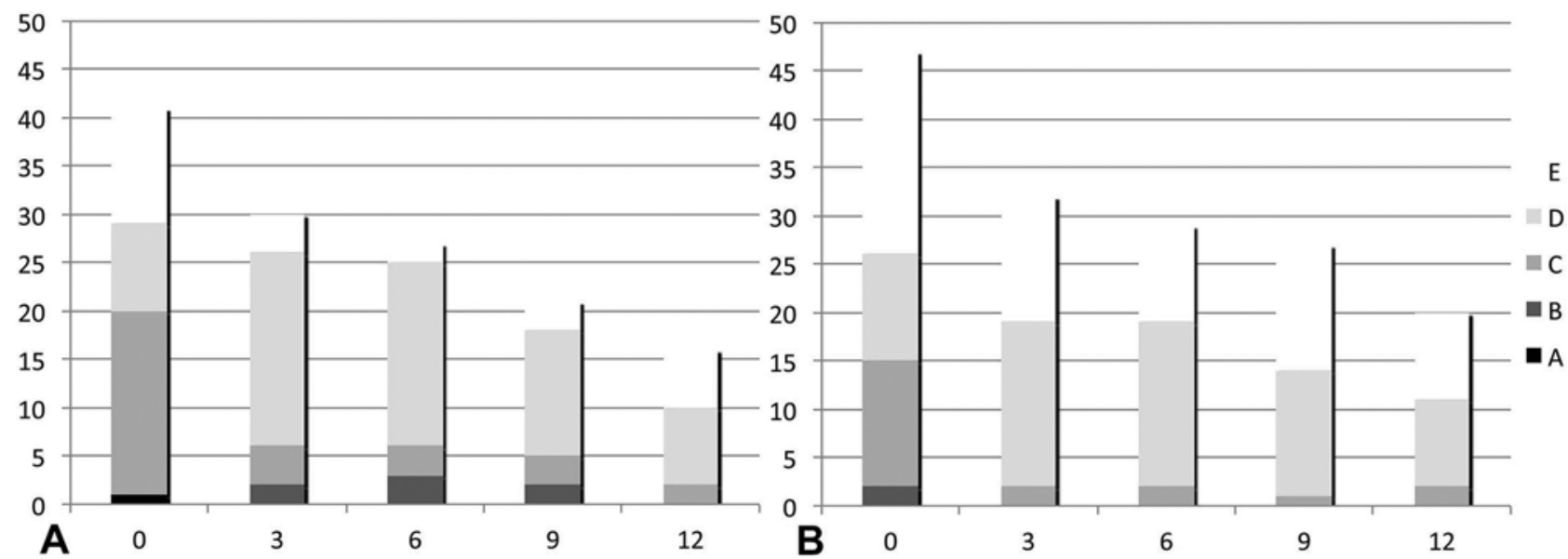

FIG. 1. Total patient numbers for Frankel grades before and at 3, 6, 9, and 12 months after decompression plus stabilization (A) and corpectomy (B).

sis. ${ }^{11}$ Disadvantages of this procedure, in our opinion, are the limited anterior decompression and, as shown in the recent study by Dong et al.,"1 the greater chance for local tumor recurrence (2 cases requiring reoperation versus none in our study). Polymethylmethacrylate (PMMA) bone cement has been suggested to have an antitumor effect because of a low reported incidence of tumor recurrence following its use. ${ }^{27}$ However, as noted by Bròdano et al., ${ }^{5}$ this effect may be attributable to the short survival of these patients. In addition, the mean operating time for the VBS procedure in the Dong et al. study (2.9 hours $\left.{ }^{11}\right)$ was only slightly shorter than that for the corpectomy procedure in our study, which also included placement of an expandable cage.

We acknowledge that the vertebrectomy procedure that we performed is not a total en bloc spondylectomy (as originally described by Boriani et al. ${ }^{4}$ and Tomita et al. ${ }^{25}$ ) but rather a piecemeal vertebrectomy (Grade 3 according to the GSTSG classification of tumor excision $\left.{ }^{6}\right)$. However, in our opinion, a pure en bloc procedure (either intra- or extralesional) is not indicated in the surgical treatment of spinal metastases, except in perhaps rare cases of solitary kidney and breast metastases. Furthermore, in this study we did not differentiate between palliative decompression and debulking (Grade 1 vs Grade 2 in the GSTSG study ${ }^{8}$ ) because there were only 4 cases in which a laminectomy without stabilization was performed for metastases in the posterior elements. In all other cases, the decompression was combined with a posterior stabilization procedure. The tumor was removed as much as possible to decompress the spinal cord and/or nerve roots. In cases of anterior compression, first a (bilateral) pediculotomy was performed, then tumor removal and subsequent intraoperative 3D scanning with a navigation system to determine the structure of the remaining vertebral body. In cases in which more than $50 \%$ of the vertebral body was removed, the remaining vertebral body was also resected and the defect was subsequently reconstructed with an expandable cage. Thus, our debulking strategy involves the removal of as much of the tumor as possible, which could explain why the total duration of surgery was only slightly shorter (138 minutes) than that for the corpectomy procedure including reconstruction (222 minutes; Table 1). This approach could be regarded as too aggressive for palliative surgery, but as the combined results from different centers in the GSTSG study showed, intraoperative complication rates are often surprisingly high for less invasive surgical procedures. ${ }^{8}$ This may be due to the poor clinical condition of these patients. Another explanation is that limited debulking may increase the chance for complications. In our study no significant differences in mortality and complication rates were found between the 2 different surgical groups of decompression plus stabilization versus corpectomy.

\section{Conclusions}

Quality of life can improve after different surgical procedures for spinal metastases. In our study, no significant differences were found among the different surgical strategies, including the relatively invasive corpectomy procedure. Moreover, improvement in Frankel grade, mortality rates, and complication rates were similar after the decompression plus stabilization and the corpectomy procedure.

\section{References}

1. American Society of Anesthesiolgists: New classification of physical status. Anesthesiology 24:111, 1963

2. Bartels RH, de Ruiter G, Feuth T, Arts MP: Prediction of life expectancy in patients with spinal epidural metastasis. Neuro Oncol 18:114-118, 2016

3. Bartels RH, Feuth T, van der Maazen R, Verbeek AL, Kappelle AC, André Grotenhuis J, et al: Development of a model with which to predict the life expectancy of patients with spinal epidural metastasis. Cancer 110:2042-2049, 2007

4. Boriani S, Biagini R, De Iure F, Bertoni F, Malaguti MC, Di Fiore M, et al: En bloc resections of bone tumors of the thoracolumbar spine. A preliminary report on 29 patients. Spine (Phila Pa 1976) 21:1927-1931, 1996

5. Bròdano GB, Cappuccio M, Gasbarrini A, Bandiera S, De Salvo F, Cosco F, et al: Vertebroplasty in the treatment of vertebral metastases: clinical cases and review of the literature. Eur Rev Med Pharmacol Sci 11:91-100, 2007

6. Choi D, Crockard A, Bunger C, Harms J, Kawahara N, Mazel C, et al: Review of metastatic spine tumour classification and indications for surgery: the consensus statement of the 
Global Spine Tumour Study Group. Eur Spine J 19:215-222, 2010

7. Choi D, Fox Z, Albert T, Arts M, Balabaud L, Bunger C, et al: Prediction of quality of life and survival after surgery for symptomatic spinal metastases: a multicenter cohort study to determine suitability for surgical treatment. Neurosurgery 77:698-708, 2015

8. Choi D, Fox Z, Albert T, Arts M, Balabaud L, Bunger C, et al: Rapid improvements in pain and quality of life are sustained after surgery for spinal metastases in a large prospective cohort. Br J Neurosurg 30:337-344, 2016

9. Choi D, Morris S, Crockard A, Albert T, Bunger C, Fehlings M, et al: Assessment of quality of life after surgery for spinal metastases: position statement of the Global Spine Tumour Study Group. World Neurosurg 80:e175-e179, 2013

10. de Ruiter GC, Lobatto DJ, Wolfs JF, Peul WC, Arts MP: Reconstruction with expandable cages after single- and multilevel corpectomies for spinal metastases: a prospective case series of 60 patients. Spine J 14:2085-2093, 2014

11. Dong L, Tan M, Wu D, Yi P, Yang F, Tang X, et al: Palliative surgery for spinal metastases using posterior decompression and fixation combined with intra-operative vertebroplasty. Clin Spine Surg [epub ahead of print], 2016

12. EuroQol Group: EuroQol-a new facility for the measurement of health-related quality of life. Health Policy 16:199208, 1990

13. Falicov A, Fisher CG, Sparkes J, Boyd MC, Wing PC, Dvorak MF: Impact of surgical intervention on quality of life in patients with spinal metastases. Spine (Phila Pa 1976) 31:2849-2856, 2006

14. Fisher CG, DiPaola CP, Ryken TC, Bilsky MH, Shaffrey CI, Berven SH, et al: A novel classification system for spinal instability in neoplastic disease: an evidence-based approach and expert consensus from the Spine Oncology Study Group. Spine (Phila Pa 1976) 35:E1221-E1229, 2010

15. Fisher CG, Schouten R, Versteeg AL, Boriani S, Varga PP, Rhines LD, et al: Reliability of the Spinal Instability Neoplastic Score (SINS) among radiation oncologists: an assessment of instability secondary to spinal metastases. Radiat Oncol 9:69, 2014

16. Fourney DR, Frangou EM, Ryken TC, Dipaola CP, Shaffrey CI, Berven SH, et al: Spinal instability neoplastic score: an analysis of reliability and validity from the spine oncology study group. J Clin Oncol 29:3072-3077, 2011

17. Frankel HL, Hancock DO, Hyslop G, Melzak J, Michaelis LS, Ungar GH, et al: The value of postural reduction in the initial management of closed injuries of the spine with paraplegia and tetraplegia. Paraplegia 7:179-192, 1969

18. Ibrahim A, Crockard A, Antonietti P, Boriani S, Bünger C, Gasbarrini A, et al: Does spinal surgery improve the quality of life for those with extradural (spinal) osseous metastases? An international multicenter prospective observational study of 223 patients. Invited submission from the Joint Section Meeting on Disorders of the Spine and Peripheral Nerves, March 2007. J Neurosurg Spine 8:271-278, 2008

19. Karnofsky DA, Abelmann WH, Craver LF, Burchenal JH: The use of the nitrogen mustards in the palliative treatment of carcinoma. With particular reference to bronchogenic carcinoma. Cancer 1:634-656, 1948
20. Patchell RA, Tibbs PA, Regine WF, Payne R, Saris S, Kryscio RJ, et al: Direct decompressive surgical resection in the treatment of spinal cord compression caused by metastatic cancer: a randomised trial. Lancet 366:643-648, 2005

21. Quan GM, Vital JM, Aurouer N, Obeid I, Palussière J, Diallo $A$, et al: Surgery improves pain, function and quality of life in patients with spinal metastases: a prospective study on 118 patients. Eur Spine J 20:1970-1978, 2011

22. Sciubba DM, Nguyen T, Gokaslan ZL: Solitary vertebral metastasis. Orthop Clin North Am 40:145-154, viii, 2009

23. Tokuhashi Y, Matsuzaki H, Oda H, Oshima M, Ryu J: A revised scoring system for preoperative evaluation of metastatic spine tumor prognosis. Spine (Phila Pa 1976) 30:2186-2191, 2005

24. Tomita K, Kawahara N, Kobayashi T, Yoshida A, Murakami H, Akamaru T: Surgical strategy for spinal metastases. Spine (Phila Pa 1976) 26:298-306, 2001

25. Tomita K, Toribatake Y, Kawahara N, Ohnari H, Kose H: Total en bloc spondylectomy and circumspinal decompression for solitary spinal metastasis. Paraplegia 32:36-46, 1994

26. van der Linden YM, Dijkstra SP, Vonk EJ, Marijnen CA, Leer JW: Prediction of survival in patients with metastases in the spinal column: results based on a randomized trial of radiotherapy. Cancer 103:320-328, 2005

27. Weill A, Chiras J, Simon JM, Rose M, Sola-Martinez T, Enkaoua E: Spinal metastases: indications for and results of percutaneous injection of acrylic surgical cement. Radiology 199:241-247, 1996

28. Wu J, Zheng W, Xiao JR, Sun X, Liu WZ, Guo Q: Health-related quality of life in patients with spinal metastases treated with or without spinal surgery: a prospective, longitudinal study. Cancer 116:3875-3882, 2010

\section{Disclosures}

Dr. Arts is a consultant for Zimmer Biomet, Silony, Amedica, EIT, and InSpine; holds a patent with EIT; and has received support from Amedica, Zimmer Biomet, and Intrinsics for nonstudy-related clinical or research efforts. Dr. Wolfs is a consultant for Zimmer Biomet, Silony, and InSpine and holds a patent with EIT.

\section{Author Contributions}

Conception and design: de Ruiter. Acquisition of data: de Ruiter, Nogarede, Wolfs. Analysis and interpretation of data: de Ruiter, Wolfs, Arts. Drafting the article: de Ruiter, Arts. Critically revising the article: all authors. Reviewed submitted version of manuscript: de Ruiter, Nogarede. Approved the final version of the manuscript on behalf of all authors: de Ruiter. Statistical analysis: de Ruiter. Administrative/technical/material support: Nogarede. Study supervision: de Ruiter, Arts.

\section{Correspondence}

Godard C. W. de Ruiter, Department of Neurosurgery, Medical Center Haaglanden, Lijnbaan 32, The Hague, Zuid-Holland 2501CK, The Netherlands. email: g.de.ruiter@mchaaglanden.nl. 